\title{
REQUISITOS ESSENCIAIS PARA A ATRATIVIDADE E A PERMANÊNCIA NA CARREIRA DOCENTE*
}

\author{
Gisele Masson ${ }^{1}$
}

\begin{abstract}
RESUMO: O artigo aborda a valorização de professores no Brasil, em sua complexidade e abrangência (considerando as condiçóes de trabalho, o salário e a carreira, a formaçáo inicial e continuada), e um conjunto de requisitos que podem ser considerados como parâmetros para a análise de planos de carreira. As reflexóes apresentadas são resultados de pesquisa documental dos atos normativos e leis que regulamentam os planos de carreira e remuneração dos professores bem como de dados estatísticos que abordam a realidade da carreira docente. $\mathrm{O}$ contexto de disparidades e contradiçóes em que muitos professores se encontram indica a necessidade de enfrentamento do desafio de se garantir as condiçóes necessárias para a atratividade e a permanência dos professores na carreira do magistério.
\end{abstract}

Palavras-chave: Política educacional. Valorização de professores. Planos de carreira e remuneração. Requisitos para atratividade e permanência.

\section{ESSENTIAL REQUIREMENTS FOR ATTRACTION AND RETENTION IN TEACHING CAREER}

ABSTRACT: This article approaches the teacher appreciation in Brazil, in its complexity and coverage (considering the working conditions, the salary, the career, the initial and continuing formation), and a set of requirements that can be considered as parameters for the analysis of career plans. The ideas presented are the results of a documental research of normative acts of laws that regulate the career plans and remuneration of teachers as well as statistical data that address the reality of teaching career. The context of disparities and contradictions in which many teachers are indicates the need to face the challenge of ensuring the necessary conditions for the attraction and retention of teachers in teaching career.

Keywords: Educational policy. Teacher appreciation. Career plans and remuneration. Requirements for attraction and retention.

\footnotetext{
*O artigo é resultado da pesquisa Politicas de formação e valorização de professores: análise das contradiçōes entre a legislação e a realidade brasileira.

${ }^{1}$ Programa de Pós-Graduação em Educação da Universidade Estadual de Ponta Grossa (UEPG) - Ponta

Grossa (PR), Brasil. E-mail: gimasson@uol.com.br

DOI: 10.1590/ES0101-73302017169078
} 


\title{
DES EXIGENCES ESSENTIELLES POUR L'ATTRACTIVITÉ ET LA PERMANENCE DANS LA CARRIÈRE D'ENSEIGNANT
}

\begin{abstract}
RÉSUMÉ: L'article traite de l'appréciation des enseignants au Brésil, dans sa complexité et son amplitude (compte tenu les conditions de travail, le salaire et la carrière, la formation initiale et continue), et un ensemble d'exigences qui peuvent être considérées comme des paramètres pour l'analyse des plans de carrière. Les idées présentées sont les résultats de la recherche documentaire des actes normatifs et les lois qui régissent les plans de carrière et de rémunération des enseignants, ainsi que des statistiques qui abordent la réalité de la carrière d'enseignant. Le contexte de différences et contradictions dans lequel de nombreux enseignants se trouvent indique la nécessité de confronter le défi d'assurer les conditions nécessaires à l'attractivité et la permanence des enseignants dans la carrière du magistère.
\end{abstract}

Mots-clés: Politique éducative. L'appréciation des enseignants. Les plans de carrière et de rémunération. Exigences pour l'attractivité et la permanence.

\section{Introdução}

A valorização dos professores, no Brasil, tem sido um tema recorrente nos debates sindicais, acadêmicos, governamentais e naqueles promovidos pelos meios de comunicação. No entanto, há vários problemas que impedem que esses profissionais, de fato, sejam valorizados. Consideramos que o tema da valorização de professores é abrangente porque envolve condiçóes de trabalho, salário e carreira, formação inicial e continuada, o que acaba dificultando a garantia efetiva de sua valorização. Neste artigo, pretendemos desenvolver uma reflexão sobre o que julgamos como requisitos essenciais para a atratividade e a permanência na carreira docente, a partir de dados da realidade brasileira. A discussão dos requisitos é importante porque há muitas divergências sobre o entendimento dos elementos que caracterizam uma carreira profissional atrativa.

Há uma tendência em se colocar o professor no centro do processo de melhoria da qualidade educação. No entanto, entendemos que é necessário ampliar a questão, destacando que a valorização profissional é um direito de qualquer trabalhador, de modo que esse tenha condiçóes de acesso aos bens materiais e culturais que o permitam ter qualidade de vida. Nessa perspectiva, utilizamos o seguinte conceito de valorização do professor, elaborado por Grochoska (2015, p. 28): “Trata-se de um princípio constitucional que se efetiva por meio de um mecanismo legal chamado carreira, que se desenvolve por meio de três elementos, sendo:

1. Formação,

2. Condições de trabalho, e 
3. Remuneração, tendo como objetivos a qualidade da educação e a qualidade de vida do trabalhador".

A partir desse conceito, destacamos que o debate em torno da valorização docente pode ser entendido como um dos elementos para a emancipação política dessa categoria, no conjunto dos demais trabalhadores. O sentido marxiano dessa emancipação significa a conquista de direitos, no contexto da sociedade capitalista, os quais, embora representem uma emancipação parcial, são fundamentais para a melhoria das condiçôes de vida do trabalhador. A inviabilidade das condições históricas para uma efetiva emancipação humana, universal, exige a luta pela ampliação e garantia de direitos, como "meios políticos de emancipaçâo", sem, contudo, perder de vista a possibilidade de desenvolvimento dos "meios humanos de emancipaçáo" (MARX, 1991). Isso pressupóe uma nova forma de organização da sociedade, ou seja, uma nova forma de organização do trabalho (trabalho associado) que supere qualquer tipo de exploraçáo do homem pelo homem e possibilite o domínio consciente do seu processo de autoconstrução.

Marx e Engels (2007, p. 50) destacaram que o primeiro pressuposto de existência humana "é de que os homens, para 'fazer história', se achem em condiçôes de poder viver. Para viver, todavia, fazem falta antes de tudo comida, bebida, moradia, vestimenta e algumas coisas mais". Assim, as lutas dos docentes por melhores condiçôes de trabalho, remuneração e manutenção de direitos são legítimas, embora tenham sido duramente enfrentadas, inclusive com o uso da violência, por governos, como, por exemplo, os do estado do Paraná, Sáo Paulo, Rio Grande do Sul e Distrito Federal. Isso contribui para a desmotivação desses profissionais, levando, em muitos casos, ao adoecimento e ao abandono da profissão, sem contar o impacto nas novas geraçóes que cada vez menos se interessam pelo ingresso na carreira docente.

Considerando os aspectos mencionados, dividimos o artigo em três partes. Na primeira, problematizamos a questão da atratividade para a escolha e a permanência na profissão docente. $\mathrm{Na}$ segunda parte, destacamos a legislação e os atos normativos que regulamentam o salário e as carreiras dos professores, assim como discutimos as disparidades na configuração dos planos de carreira no Brasil. Por último, apresentamos os requisitos que poderão contribuir no debate sobre a valorização de professores, a partir de planos de carreira mais atrativos.

\section{A atratividade da profissão docente no Brasil: entre a escolha, a permanência e o abandono}

Abordar os aspectos relacionados à atratividade das carreiras profissionais requer a consideração de questóes que envolvem os processos de trabalho de cada pro- 
fissão, como as exigências, as condições de trabalho, a remuneração etc. Desse modo, a escolha profissional e a inserçáo no mercado de trabalho vão além de uma decisáo subjetiva, pois abrangem também as condiçóes econômicas e socioculturais dos jovens.

No Brasil, a ampliação da educação escolar demanda continuamente novos docentes para atuar em diferentes níveis e modalidades. Além disso, de acordo com os dados do Instituto Brasileiro de Geografia e Estatística (IBGE), de 2013, apresentados em nota técnica do Departamento Intersindical de Estatística e Estudos Socioeconômicos (DIEESE), 46,1\% dos professores das redes estaduais e municipais de ensino possuem faixa etária acima de 40 anos, evidenciando uma demanda expressiva de novos docentes nas próximas décadas para ocupar as vagas dos que se aposentarão (IBGE, 2013 apud DIEESE, 2014).

Todavia, o desinteresse dos jovens pela profissão docente pode ser observado pela escolha dos cursos de licenciatura no momento da realizaçáo do vestibular. Na última Sinopse Estatística da Educação Superior, disponibilizada pelo Instituto Nacional de Estudos e Pesquisas Educacionais Anísio Teixeira (INEP), de 2013, constata-se que há o triplo de procura pelos bacharelados em relação às licenciaturas (BRASIL, 2013).

A pesquisa de Gatti et al. (2010), com jovens concluintes do ensino médio, revelou que $83 \%$ deles não têm interesse em ser professor. Dentre os fatores negativos da profissão que justificam o fato de não a escolherem estão:

- $\quad$ a falta de identificação pessoal (48\%);

- a baixa remuneração (25\%);

- a falta de identificação profissional (19\%);

- a desvalorização social da profissão (13\%);

- a exigência de envolvimento pessoal na profissão (10\%);

- o desinteresse e desrespeito dos alunos (10\%); e

- $\quad$ as condiçóes de trabalho (6\%).

A pesquisa com ex-professores, realizada por Lapo e Bueno (2003), apresentou os principais motivos para o pedido de exoneração do cargo de professor:

- a baixa remuneração associada às péssimas condiçôes de trabalho;

- a baixa remuneração e a oportunidade de emprego mais rentável;

- a baixa remuneraçáo associada à necessidade de tempo livre para concluir a pós-graduação;

- a baixa remuneração vinculada com a falta de perspectiva de crescimento profissional; 
- a falta de perspectiva quanto às mudanças na rede de ensino;

- o nascimento de filhos;

- a baixa remuneraçáo, mais o desencanto com a profissáo;

- a baixa remuneração associada à mudança de cidade;

- a mudança de cidade;

- a falta de condiçóes dignas de trabalho;

- a insatisfação com a estrutura do sistema educacional;

- os problemas de saúde; e

- trabalhar em negócio próprio.

Dentre as razóes, nota-se um peso consideravelmente maior para a baixa remuneraçáo, no entanto, a decisáo pelo abandono da profissão está fortemente relacionada a outros motivos que se associam à questáo salarial.

$\mathrm{Na}$ visão das autoras, o abandono da profissão:

[...] não significa apenas simples renúncia ou desistência de algo, mas o desfecho de um processo para o qual concorrem insatisfaçóes, fadigas, descuidos e desprezos com o objeto abandonado; significa o cancelamento das obrigaçóes assumidas com a instituição escolar, quando o professor pede exoneração do cargo ou, de maneira mais abrangente, o cancelamento das obrigaçôes profissionais, quando deixa de ser professor. Esse cancelamento, visto como a ruptura total dos vínculos necessários ao desempenho do trabalho pode ser decorrente da ausência parcial e/ou do enfraquecimento anterior desses vínculos (LAPO; BUENO, 2003, p.75).

Isso quer dizer que a decisão por abandonar a profissão é bastante problemática porque envolve um processo que vai desvinculando o sujeito da atividade que desenvolve pela insatisfação que se acumula ao longo da carreira. Isso talvez explique o fato de que a decisão em abandonar a profissão aconteça baseada em mais de um motivo.

O estudo de Lemos (2009) também indica que as principais razóes para o abandono são: a desvalorizaçáo profissional, a indisciplina e a violência dos alunos, os salários baixos, o ambiente negativo de trabalho, a progressão continuada, as famílias desinteressadas, as condiçôes de trabalho, dentre outras.

No que diz respeito à permanência na profissão, segundo Ens et al. (2014), essa é justificada por questóes relacionadas ao aspecto afetivo como: o gosto pela profissão, a crença na importância da educação e a realização pessoal. 
Destacam, ainda, que a permanência na profissão e a busca pela profissionalização estão mais atreladas à valorização profissional por meio de melhores salários do que ao reconhecimento. $\mathrm{Na}$ avaliação das autoras,

[...] os professores que se manifestam a favor da permanência na profissão evidenciam representaçōes fortemente atreladas ao vínculo afetivo com os alunos e com a finalidade de seu trabalho, assumido como uma missão. Nesse sentido, as representaçôes dos professores são marcadas por uma visão romantizada sem uma análise crítica dos aspectos políticos e da falta de condiçóes objetivas de trabalho, que ainda é uma realidade no país (ENS et al., 2014, p. 518-519).

Diante do que apresentamos, podemos destacar que as razóes que levam os professores a abandonarem a profissão ou a permanecerem na carreira são distintas. No entanto, a questão da remuneração tem um peso relevante, assim como a identificação com a profissão e a sua valorização social.

$\mathrm{Na}$ seção seguinte do texto, abordaremos a legislação e os atos normativos que regulamentam o salário e as carreiras dos professores no Brasil.

\section{Leis e atos normativos sobre salário e carreira: aspectos formais e reais da valorização de professores}

A discussão atual sobre a implantação de planos de carreira dos professores, embora ainda necessária, é tardia, considerando que a Constituição Federal de 1988, no artigo 206, no inciso V, já previa a "valorização dos profissionais da educação escolar, garantidos, na forma da lei, planos de carreira, com ingresso exclusivamente por concurso público de provas e títulos, aos das redes pública" (Redaçáo dada pela Emenda Constitucional no 53, de 2006) (BRASIL, 2006).

A Lei de Diretrizes e Bases da Educação Nacional (LDBN), de 1996, no artigo 67, também destaca que:

Os sistemas de ensino promoverão a valorização dos profissionais da educação, assegurando-lhes, inclusive nos termos dos estatutos e dos planos de carreira do magistério público: I - ingresso exclusivamente por concurso público de provas e títulos; II - aperfeiçoamento profissional continuado, inclusive com licenciamento periódico remunerado para esse fim; III - piso salarial profissional; IV - progressão funcional baseada na titulação ou habilitação, e na avaliação do desempenho; V período reservado a estudos, planejamento e avaliação, incluído na carga de trabalho; VI - condições adequadas de trabalho (BRASIL, 1996). 
A partir dessas duas leis gerais, foi elaborada a Resolução CNE/CEB no 3, de 1997, a fim de definir as Diretrizes para os Planos de Carreira e Remuneraçáo para o Magistério dos estados, do Distrito Federal e dos municípios (BRASIL, 1997). No entanto, Machado (2010) destaca que a aprovação dessa resolução não representou avanços em termos de valorizaçáo salarial dos professores. Em 2009 foram definidas as novas Diretrizes Nacionais para os Planos de Carreira e Remuneração dos Profissionais do Magistério da Educação Básica Pública, com a Resolução CNE/CEB no 2. Nessa resolução, ficou estabelecido, em seu artigo $3^{\circ}$, que:

Os critérios para a remuneração dos profissionais do magistério devem pautar-se nos preceitos da Lei no $11.738 / 2008$, que estabelece o Piso Salarial Profissional Nacional, e no Artigo 22 da Lei $n^{\circ} 11.494 / 2007$, que dispóe sobre a parcela da verba do Fundo de Manutenção e Desenvolvimento da Educação Básica e Valorização do Magistério (FUNDEB) destinada ao pagamento dos profissionais do magistério, bem como no Artigo $69 \mathrm{da}$ Lei no 9.394/96, que define os percentuais mínimos de investimento dos entes federados na educação (BRASIL, 2009, p. 1).

A Lei $\mathrm{n}^{\circ} 11.738$, de 16 de julho de 2008, instituiu um Piso Salarial Profissional Nacional (PSPN) para professores com nível médio, com uma jornada de 40 horas semanais e limite máximo de dois terços da carga horária para o desempenho de atividades de interaçáo com os alunos ( $1 / 3$ seria destinado para a hora-atividade) (BRASIL, 2008).

Muitos estados e municípios têm alegado dificuldades financeiras no cumprimento da lei do piso. Na visão de Lisboa (2015, p. 1054), "essa situação poderá gerar conflitos jurídicos entre os professores e as prefeituras na cobrança retroativa dos vencimentos". Além disso, o autor destaca duas questóes importantes: a primeira diz respeito à complementaçáo da Uniáo nos casos em que o ente federado não tenha disponibilidade orçamentária; a segunda se refere à obrigatoriedade dos entes federados de elaborar ou readequar os planos de carreira dos professores.

A questão da suplementação da União não é tão simples, pois é necessário justificar a demanda por meio de uma planilha de custos que passa por análise pela Comissão Intergovernamental de Financiamento para a Educação Básica de Qualidade ${ }^{1}$. Além disso, a fixação de um valor mínimo para os professores com nível médio não tem garantido uma adequada diferença salarial em relação aos que possuem formação em nível superior.

O atual Plano Nacional de Educaçáo (PNE), Lei no 13.005, de 25 de junho de 2014, determinou que os estados e os municípios implementassem ou revisassem os seus planos de carreira até 2016. Nas estratégias do PNE, há a indicação da necessidade de implantaçáo gradual do cumprimento da jornada de 
trabalho em um único estabelecimento escolar, a previsão de licenças remuneradas e incentivos para qualificação profissional e o acompanhamento do cumprimento do PSPN (BRASIL, 2014).

Embora exista regulamentação para a organização dos planos de carreira dos professores, essa se dá de forma muito variada, com uma diversidade de critérios e formatos que dificultam a definição dos requisitos mínimos indispensáveis para a carreira docente e a garantia de uma adequada valorização dos professores. Essa diversidade se refere às disparidades em relação ao vencimento inicial e à remuneração final ${ }^{2}$, entre estados e municípios, ao percentual atribuído a cada elevação de nível, ao tempo de interstício entre as classes, aos coeficientes relativos à progressáo ao longo da carreira, às formas de definição de nível, classe, referência, promoção horizontal, vertical e diagonal, dentre outros aspectos.

Por um lado, entendemos que é necessário que os planos estejam adequados às diferentes características e necessidades das redes estaduais e municipais de ensino, por outro lado, consideramos a importância de um delineamento mínimo para a induçáo do planejamento de planos mais adequados do ponto de vista da efetiva valorização dos professores, uma vez que há disparidades injustificáveis, as quais têm desmotivado o ingresso e a permanência na profissão.

O documento Plano Nacional de Educação PNE 2014-2024: Linha de Base, elaborado pela Diretoria de Estudos Educacionais (DIRED), do Instituto Nacional de Estudos e Pesquisas Educacionais Anísio Teixeira (INEP), apresenta indicadores para o monitoramento do PNE (BRASIL, 2014). Nesse documento destaca-se que:

O levantamento realizado pela Diretoria de Valorizaçáo dos Profissionais da Educação (Divape/Sase/MEC), entre os meses de março a abril de 2015, com 26 estados da Federaçáo e o Distrito Federal, demonstra que 33,3\% não pagam o valor do PSPN, atualizado em janeiro de 2015 . Da mesma forma, 40,7\% não estruturam a jornada de trabalho conforme a Lei no $11.738 / 2008$. O mesmo levantamento foi feito em 26 capitais brasileiras. Destas, $23,1 \%$ não pagam o valor atualizado do PSPN e 61,5\% não estruturam a jornada de trabalho de acordo com que estabelece a citada lei (BRASIL, 2015, p. 304).

Em linhas gerais, podemos afirmar que há uma disparidade significativa entre os estados no que diz respeito à remuneraçáo dos professores e ao cumprimento da lei do PSPN.

Diante dessa realidade, o Ministério da Educação publicou a Portaria no 369, de 05 de maio de 2016, a qual instituiu o Sistema Nacional de Avaliação da Educação Básica (SINAEB), incluindo como uma de suas diretrizes a valorização dos profissionais da educação, por meio das seguintes dimensões: formação inicial e continuada, satisfação profissional, carreira e remuneração (BRASIL, 2016a). 
Na sequência, a Portaria no 387, de 10 de maio de 2016, foi exarada com o objetivo de instituir a Rede de Assistência Técnica dos Planos de Carreira e Remuneração para o desenvolvimento de atividades de formaçáo dos secretários estaduais e municipais, com o objetivo de adequar os planos à legislação vigente. Essa importante iniciativa possibilitou a organização de um site $^{3}$ com informaçóes e orientaçóes sobre planos de carreira dos profissionais da educação (BRASIL, 2016b).

Essas ações indicam que há, no Brasil, uma preocupação em atrair e manter os professores, considerando o quadro preocupante em que se encontram. Assim, com o intuito de contribuir para o debate sobre planos de carreira atrativos para o exercício da profissão docente, apresentaremos, na seção seguinte, os requisitos que julgamos importantes para a valorizaçáo desse profissional.

\section{Requisitos para a atração e a retenção dos professores na carreira docente}

A definição de critérios gerais que sirvam de parâmetro para a elaboração e/ou atualização de planos de carreira para os professores é importante, considerando o contexto de disparidades e contradiçōes evidenciado pelas questóes apresentadas anteriormente. Destacamos, portanto, alguns requisitos essenciais para a atratividade na carreira docente.

1. Remuneração proporcional à formação com equiparação às demais profissóes com formação equivalente: esse requisito é importante porque o PSPN define um valor mínimo a ser pago como vencimento inicial aos docentes que possuem nível médio de formação, para uma jornada de trabalho de 40 horas semanais. Contudo, o mínimo tem sido considerado como o máximo, pois muitos professores ingressam na carreira com nível superior, mas recebem somente o piso correspondente ao nível médio. Sobre isso, a Confederação Nacional dos Trabalhadores em Educação (CNTE, 2015) defende o estabelecimento de um acréscimo de 50\% para quem tem formação superior, já que ainda há um número considerável de profissionais atuando, especialmente na educação infantil e nos anos iniciais do ensino fundamental, com formação em nível médio ou pós-médio.

Outro problema é que muitos gestores municipais estão rebaixando as exigências de formação nos concursos públicos, a fim de pagarem somente o piso aos professores, já que esses teriam apenas o nível médio. Tal iniciativa vai na contramáo do que foi estabelecido no Plano Nacional de Educaçáo (PNE 2014-2024), o qual prevê, na Meta 15, que seja "assegurado que todos os professores e as professoras da educação básica possuam formação específica de nível superior, obtida em curso de licenciatura na área de conhecimento em 
que atuam" (BRASIL, 2014). Essa questão tem sido motivo de reivindicação de muitas entidades representativas dos docentes, a exemplo da Associação Nacional pela Formação dos Profissionais da Educação (ANFOPE).

No que diz respeito às demais profissóes, os professores têm os seus salários significativamente inferiores, mesmo tendo o mesmo nível de formação. Isso pode ser observado nos dados apresentados por Maciente, Nascimento e Assis (2013), em que os profissionais da educação ocupam as últimas colocaçóes de uma lista de 109 ocupaçóes, sistematizados na Tabela 1.

As informações apresentadas na tabela contribuem para explicar o problema da atratividade e da permanência na carreira docente, já que os professores têm uma remuneração significativamente inferior à de outras profissóes com o mesmo nível de formação.

De acordo com o Observatório do PNE (2014), os professores recebem, em média, $57,3 \%$ do salário de outros profissionais. A meta do PNE é que, em 2020 , todos os profissionais da educação recebam de forma equivalente ao rendimento médio dos demais profissionais com a mesma titulação. Diante disso, haverá a necessidade de um grande esforço dos entes federados para que essa meta possa ser atingida no prazo estipulado.

\section{Tabela 1}

Ranking das ocupaçóes, considerando área de trabalho e salário, com formação em nível superior - 2012 .

\begin{tabular}{l|c|c}
\hline $\begin{array}{l}\text { Ranking } \\
\text { por salário }\end{array}$ & Carreira & Salário mensal \\
\hline $1^{\circ}$ & Pesquisadores de engenharia e tecnologia & $\mathrm{R} \$ 12.301,35$ \\
\hline $2^{\circ}$ & Médicos clínicos & $\mathrm{R} \$ 9.505,34$ \\
\hline $3^{\circ}$ & Médicos em medicina diagnóstica e terapêutica em especialidades cirúrgicas & $\mathrm{R} \$ 8.443,94$ \\
\hline $4^{\circ}$ & Engenheiros de minas e afins & $\mathrm{R} \$ 8.056,91$ \\
\hline $5^{\circ}$ & Peritos criminais & $\mathrm{R} \$ 8.023,83$ \\
\hline $6^{\circ}$ & Engenheiros mecânicos e afins & $\mathrm{R} \$ 7.793,91$ \\
\hline $7^{\circ}$ & Engenheiros químicos e afins & $\mathrm{R} \$ 7.072,08$ \\
\hline $8^{\circ}$ & Engenheiros metalurgistas, de materiais e afins & $\mathrm{R} \$ 6.709,92$ \\
\hline $9^{\circ}$ & Professores do ensino médio & $\mathrm{R} \$ 6.874,97$ \\
\hline $10^{\circ}$ & Professores do ensino fundamental - anos finais & $\mathrm{R} \$ 2.675,93$ \\
\hline $53^{\circ}$ & Professores do ensino fundamental - anos iniciais & $\mathrm{R} \$ 2.153,25$ \\
\hline $75^{\circ}$ & Professores da educaçáo infantil & $\mathrm{R} \$ 2.063,58$ \\
\hline $93^{\circ}$ & $\mathrm{R} \$ 6.732,41$ \\
\hline $98^{\circ}$ & Ma administraçáo dos serviços de segurança & \\
\hline
\end{tabular}

Fonte: CAGED/MTE (2012 apud MACIENTE; NASCIMENTO; ASSIS, 2013), adaptada pela autora. 
2. Ascensão na carreira de acordo com o tempo de serviço e a titulaçãolformação: é fundamental que a carreira apresente a possibilidade de se avançar tanto em relação ao tempo de serviço quanto à titulação, sem desconsiderar a possibilidade de ascender, também, pela formação continuada. O número de anos previstos para alcançar o final da carreira deve garantir a continuidade da progressão até o momento da aposentadoria, pois há planos em que o professor chega muito cedo ao final da carreira e estaciona, sem nenhuma possibilidade de continuar avançando. Essa estagnação pode comprometer a motivação para a permanência na profissão, por isso, é fundamental uma progressão contínua na carreira.

3. Alcance do topo da carreira como uma possibilidade para todos e náo restrito à minoria: é importante que o plano de carreira apresente nível correspondente aos que possuem mestrado e doutorado, mas é necessário pensar em formas de valorizar a formação continuada, a fim de que o alcance ao último nível da carreira não seja uma possibilidade para poucos. Essa questáo é importante porque muitos profissionais não realizam curso de mestrado ou doutorado, mas participam de cursos de formação continuada. Desse modo, é fundamental que sejam valorizados de acordo com essa formação, a fim de que vislumbrem um horizonte de valorização ao longo de sua carreira.

4. Progressão horizontal com interstícios não muito longos: normalmente os planos de carreira preveem a ascensão horizontal, a qual se refere à passagem de um nível ou classe ${ }^{4}$, a cada período estipulado. Para que a carreira seja atrativa, é necessário que não se exija um tempo muito prolongado para a progressão, por isso a definição de dois a três anos seria um período razoável para a ascensão.

5. Valorização do professor de acordo com a sua titulaçãolformação, desde $o$ início da carreira: a remuneração do professor de acordo com a sua titulação é um direito desde o início da sua carreira. Muitos concursos públicos exigem o nível médio ou superior como o mínimo para ingressar na carreira. Entretanto, os que ingressam com titulação maior somente avançam na carreira após a passagem pelo estágio probatório ${ }^{5}$, o que acaba desestimulando a permanência na profissão. Há que se ter clara a diferença entre estabilidade e efetividade, pois a primeira é a garantia constitucional de permanência no serviço público, outorgada à pessoa que foi nomeada em caráter efetivo, após ter ultrapassado o estágio probatório de três anos. A efetividade corresponde à situação de quem foi aprovado em concurso público, pressupondo uma situaçáo de permanência na carreira. Sendo assim, todo profissional efetivo tem direito a receber um vencimento de acordo com a formação, embora não possa sair do primeiro nível do plano de carreira até que finde o estágio probatório. 
6. Dispersáo salarial ao longo da carreira que garanta a atratividade para a permanência na profissáo: embora seja frequente o professor iniciar a carreira ganhando menos que outras profissóes com o mesmo nível de formação, um plano de carreira que valorize adequadamente a formaçáo continuada e o tempo de serviço do professor pode contribuir para a permanência na profissão. A diferença entre a remuneração final e o vencimento inicial náo pode ser pequena, por isso a realização do cálculo do coeficiente de progressão permite observar quantas vezes mais é a remuneraçấo final em relação ao vencimento inicial. Esse indicador é importante para que o professor que inicia com um vencimento não muito atrativo possa se sentir motivado a permanecer na carreira pela possibilidade concreta de melhorar a sua condiçáo salarial ao longo do tempo.

7. Consideraçâa do custo de vida regional: há uma variação muito grande do custo de vida nos diferentes estados, assim como entre as regiōes dentro de um mesmo estado. Desse modo, a relação entre a remuneração e o custo de vida deve ser considerada, pois há lugares que apresentam um custo de vida elevado sem uma remuneração correspondente. Os estados que apresentam as capitais com maior custo de vida não são os que melhor remuneram os seus professores ${ }^{6}$. Desse modo, a comparação entre a remuneração dos professores dos diferentes estados náo prescinde essa questáo, pois pode parecer que um estado remunera melhor que outro, no entanto, o custo de vida é superior aos demais.

A apresentação dos requisitos que julgamos essenciais para a atratividade e a permanência da carreira do magistério teve o objetivo de contribuir para problematizar os elementos que configuram os planos de carreira e remuneração, e indicar possibilidades de planejamento que de fato possam garantir a valorizaçấo dos professores, no que diz respeito à dimensão econômica. Todavia, temos claro que esse conjunto de requisitos não esgotam as questóes que têm levado ao abandono da profissão docente, mas podem ser tomados como parâmetros iniciais para uma adequaçáo dos planos de carreira dos professores com vistas à valorizaçáo profissional.

\section{Considerações finais}

Neste artigo, procuramos contribuir no debate sobre a valorizaçáo dos professores brasileiros a partir de questóes apresentadas por autores que têm pesquisado o tema, assim como dos aspectos jurídicos que possibilitam avançar na questão da valorização dos professores. Buscamos destacar também alguns limites que não têm favorecido a atratividade e a permanência na profissão docente, como 
os baixos salários, as inadequadas condições de ascensão na carreira, a desvalorização da formação se comparada com outros profissionais, dentre outros aspectos.

Diante disso, sistematizamos alguns requisitos que consideramos fundamentais para que os planos de carreira dos professores possam promover o interesse pela profissão docente, bem como a permanência nela. Reafirmamos, portanto, a importância da remuneraçáo e da ascensão na carreira profissional, a partir da formação, desde o ingresso; da passagem de um nível para outro da carreira sem exigência de um tempo prolongado; da remuneração, ao final da carreira, significativamente maior do que o vencimento inicial; da consideração das condiçóes de vida local na definição da remuneração, a fim de que o rendimento do professor seja compatível com o custo de vida; da perspectiva de se chegar ao final da carreira para o coletivo dos professores e náo apenas para uma minoria.

A definição desses requisitos não esgota as possibilidades de se avançar na questão da valorização dos professores no Brasil, mas julgamos que poderão ser tomados como ponto de partida para a análise e a implementaçáo de planos de carreira que contribuam para a promoção de uma melhor condição de vida e de trabalho aos professores.

Enfatizamos a importância da valorização do professor, entendida como um direito, o qual ainda necessita ser garantido e ampliado. Os professores fazem parte de uma categoria profissional que recebe menos do que outros profissionais com a mesma formação e, embora saibamos da impossibilidade ontológica do Estado ser mediador para a superação das formas desiguais de vida e trabalho na sociedade capitalista, é fundamental a organização coletiva desses profissionais para a manutenção, garantia e ampliação de direitos no plano legal.

\section{Notas}

1. Comissão instituída pelo Ministério da Educação, de acordo com a Lei no 11.494 , de 2007, composta por membros do MEC, do Conselho Nacional de Secretários de Educação (Consed) e da União Nacional dos Dirigentes Municipais de Educação (Undime) (BRASIL, 2007). Tal Comissão Nacional definiu critérios para a complementação do piso, por meio da Resolução $n^{\circ} 5$, de 22 de fevereiro de 2011, aprovada pela Portaria no 213, de 2 de março de 2011 (BRASIL, 2011).

2. Camargo et al. (2009) esclarece que o "salário" é o montante pago pelo empregador a título de retribuição pelo trabalho realizado; o termo "vencimento" é definido como retribuição pecuniária pelo exercício de uma atividade, com valor fixado em lei; o conceito de "remuneraçãa" pode ser definido como a soma de todos os benefícios financeiros, dentre eles o salário.

3. O endereço do site é http://planodecarreira.mec.gov.br/. Nesse site é possível acessar o Sistema de Apoio à Gestão do Plano de Carreira e Remuneração - SisPCR, desenvolvido pelo Ministério da Educação - MEC. 
4. Os planos de carreira de estados e municípios conceituam de forma diferente classe e nivel. Em alguns, a classe se refere à ascensão vertical, obtida de acordo com a titulação/formação, em outros, ela se refere à ascensão horizontal, obtida conforme o tempo de serviço; o mesmo ocorre com o uso do termo nível. Há, ainda, em alguns planos de carreira, a previsão de ascensão diagonal, obtida por merecimento, e o uso do termo referência, com diferentes significados.

5. Há jurisprudências que reconhecem o direito à progressão funcional durante o interregno do estágio probatório. Consultar: http://www.jusbrasil.com.br/jurisprudencia/busca?q=PROGRESSAO+FUNCIONAL+DURANTE+EST\%C3\%81GIO+PROBAT\%C3\%93RIO.

6. Os estados que apresentam as capitais com maior custo de vida não são os que melhor remuneram os seus professores: São Paulo (SP), Rio de Janeiro (RJ), Florianópolis (SC) (DIEESE, 2016). Os estados que apresentam o melhor vencimento inicial para os professores da rede estadual de ensino são: Mato Grosso do Sul, Mato Grosso, Distrito Federal, Tocantins e Roraima, respectivamente.

\section{Referências}

BRASIL. Constituição da República Federativa do Brasil de 1988. Brasília, 1988. Disponível em: shttp://www.planalto.gov.br/ccivil 03/constituicao/constituicaocompilado. $>$. Acesso em: 7 dez. 2015.

. Emenda Constitucional n. ${ }^{\circ}$ 53, de 19 de dezembro de 2006. Dá nova redaçáo aos arts. 7., 23, 30, 206, 208, 211 e 212 da Constituiçấo Federal e ao art. 60 do Ato das Disposiçóes Constitucionais Transitórias. Diário Oficial da União, Brasília, 2006. Disponível em: <http://www. planalto.gov.br/ccivil 03/constituicao/emendas/emc/emc53.htm>. Acesso em: $10 \mathrm{dez} .2015$.

Instituto Nacional de Estudos e Pesquisas Educacionais Anísio Teixeira. Sinopses estatísticas da educação superior - graduação. 2013. Disponível em: <http://portal.inep.gov. br/superior-censosuperior-sinopse $>$. Acesso em: 14 mar. 2016.

. Lei n. ${ }^{\circ}$ 9.394, de 20 de dezembro de 1996. Estabelece as diretrizes e bases da educação nacional. Diário Oficial da União, Brasília, 1996. Disponível em: $\leq$ http://www. planalto.gov.br/ccivil 03/leis/19394.htm>. Acesso em: 8 dez. 2015.

Lei n. ${ }^{\circ} 11.494$, de 20 de junho de 2007. Regulamenta o Fundo de Manutenção e Desenvolvimento da Educação Básica e de Valorização dos Profissionais da Educação - FUNDEB, de que trata o art. 60 do Ato das Disposiçóes Constitucionais Transitórias; altera a Lei n. ${ }^{\circ} 10.195$, de 14 de fevereiro de 2001; revoga dispositivos das Leis $n .^{\text {os }}$ 9.424, de 24 de dezembro de 1996, 10.880, de 9 de junho de 2004, e 10.845, de 5 de março de 2004; e dá outras providências. Diário Oficial da União, Brasília, 2007. Disponível em: shttp://www.planalto.gov.br/ccivil 03/ ato2007-2010/2007/lei/ 111494.htm>. Acesso em: 21 mar. 2016.

. Lei n. ${ }^{\circ} 11.738$, de 16 de julho de 2008. Regulamenta a alínea "e" do Inciso III do caput do art. 60 do Ato das Disposiçóes Constitucionais Transitórias, para instituir o piso salarial profissional nacional para os profissionais do magistério público da educação básica. Diário Oficial da Uniāo, Brasília, 2008. Disponível em: <http://www.planalto.gov. br/ccivil 03/ ato2007-2010/2008/lei/111738.htm>. Acesso em: 3 abr. 2016. 
Lei n. ${ }^{\circ}$ 13.005, de 25 de junho de 2014. Aprova o Plano Nacional de Educaçáo - PNE e dá outras providências. Diário Oficial da União, Brasília, 2014. Disponível em: <http://www2.camara.leg.br/legin/fed/lei/2014/lei-13005-25-junho-2014-778970publicacaooriginal-144468-pl.html>. Acesso em: 27 mar. 2016.

- Ministério da Educação. Conselho Nacional de Educação. Câmara de Educação Básica. Resolução n. ${ }^{\circ}$ 2, de 28 de maio de 2009. Fixa as Diretrizes Nacionais para os Planos de Carreira e Remuneraçáo dos Profissionais do Magistério da Educação Básica Pública, em conformidade com o artigo $6 .^{\circ}$ da Lei n. ${ }^{\circ} 11.738$, de 16 de julho de 2008, e com base nos artigos 206 e 211 da Constituição Federal, nos artigos 8. ${ }^{\circ}$, $\$ 1 .^{\circ}$, e 67 da Lei n. ${ }^{\circ}$ 9.394, de 20 de dezembro de 1996, e no artigo 40 da Lei n. ${ }^{\circ} 11.494$, de 20 de junho de 2007. Diário Oficial da União, Brasília, 2009. Disponível em: <http://portal.mec.gov. br/dmdocuments/resolucao cne ceb002 2009.pdf>. Acesso em: 13 nov. 2015.

. Ministério da Educação. Conselho Nacional de Educação. Câmara de Educação Básica. Resolução n.o 3, de 8 de outubro de 1997. Fixa Diretrizes para os Novos Planos de Carreira e de Remuneração para o Magistério dos Estados, do Distrito Federal e dos Municípios. Diário Oficial da União, Brasília, 1997. Disponível em: <http://portal.mec. gov.br/cne/arquivos/pdf/CEB0397.pdf>. Acesso em: 5 dez. 2015.

. Ministério da Educação. Secretaria Executiva. Instituto Nacional de Estudos e Pesquisas Educacionais Anísio Teixeira. Diretoria de Estudos Educacionais. Plano Nacional de Educação PNE 2014-2024: Linha de Base. Brasília: Inep, 2015.

.Ministério da Educação. Portarian. ${ }^{\circ} 369$, de 5 de maio de 2016. Instituio Sistema Nacional da Educação Básica - SINAEB. Diário Oficial da União, Brasília, 2016a. Disponível em: shttp:// pesquisa.in.gov.br/imprensa/jsp/visualiza/index.jsp?jornal=1\&pagina=26\&data=06/05/2016> . Acesso em: 20 jun. 2016.

. Ministério da Educação. Portaria n. ${ }^{\circ}$ 387, de 10 de maio de 2016. Institui a Rede de Assistência Técnica dos Planos de Carreira e Remuneração. Diário Oficial da União, 2016b. Disponível em: shttp://planodecarreira.mec.gov.br/images/pdf/Legislacoes/ portaria_387_2016_rede_PCR.pdf>. Acesso em: 20 jun. 2016.

Portaria no 213, de 2 de março de 2011. Aprova a Resoluçáo no 5, de 22 de fevereiro de 2011, da Comissão Intergovernamental de Financiamento para a Educaçáo Básica de Qualidade. Diário Oficial da União, 2011. Disponível em: shttp://portal. mec.gov.br/index.php?option =com docman \&view=download\&alias=7628-pn4pdf\&Itemid=30192>. Acesso em: 21 mar. 2016.

CAMARGO, R.B.; GOUVEIA, A.B.; GIL, J.; MINHOTO, M.A.P. Financiamento da educação e remuneração docente: um começo de conversa em tempos de piso salarial. Revista Brasileira de Política e Administração da Educação, v. 25, n. 2, p. 341-363, maio/ago. 2009.

CNTE - Confederação Nacional dos Trabalhadores em Educação. Educadores aprovam projeto de piso nacional profissional para toda a categoria. 2015. Disponível em: <http:// www.cnte.org.br/index.php/comunicacao/noticias/15353-educadores-aprovam-projetode-piso-nacional-profissional-para-toda a categoria.html>. Acesso em: 13 jul. 2016.

DIEESE - Departamento Intersindical de Estatística e Estudos Socioeconômicos. Comportamento do custo da Cesta Básica se diferencia nas capitais do Brasil. 2016. Disponível em: <http://www. dieese.org.br/analisecestabasica/2016/201603cestabasica.pdf 7. Acesso em: 15 abr. 2016. 
Transformaçóes recentes no perfil do docente das escolas estaduais e municipais de educação básica: uma análise a partir dos dados da Pnad. Nota Técnica, n. 141, 2014. Disponívelem: $\leq$ http://www.dieese.org.br/notatecnica/2014/notaTec141DocentesPnadvf. pdf $>$. Acesso em: 25 jul. 2016.

ENS, R.T.; EYNG, A.M.; GISI, M.L.; RIBAS, M.S. Evasão ou permanência na profissão: políticas educacionais e representaçōes sociais de professores. Diálogo Educacional, Curitiba, v. 14, n. 42, p. 501-523, maio/ago. 2014.

GATTI, B.A.; TARTUCE, G.L.B.P.; NUNES, M.M.R.; ALMEIDA, P.C.A. A atratividade da carreira docente no Brasil. Estudos \& Pesquisas Educacionais, São Paulo, n. 1, maio 2010.

GROCHOSKA, M.A. Políticas educacionais e a valorização do professor: carreira e qualidade de vida dos professores de educação básica do município de São José dos Pinhais/PR. 269f. Tese (Doutorado em Educação). Universidade Federal do Paraná, Curitiba, 2015.

LAPO, F.R.; BUENO, B.O. Professores, desencanto com a profissão e abandono do magistério. Cadernos de Pesquisa, São Paulo, n. 118, p. 65-88, mar. 2003.

LEMOS, J.C.G. Do encanto ao desencanto, da permanência ao abandono: o trabalho docente e a construção da identidade profissional. 315 f. Tese (Doutorado em Educação). Pontifícia Universidade Católica de São Paulo, São Paulo, 2009.

LISBOA, G.J. Federalismo educacional esfacelado? Um estudo de caso sobre o piso salarial. Ensaio: Avaliaçâo e Políticas Públicas em Educaçâo, Rio de Janeiro, v. 23, n. 89, p. 1040-1074, out./dez. 2015.

MACHADO, J.P. Piso salarial profissional nacional do magistério: conflitos e limites de sua implantação na rede pública estadual de Goiás. 219 f. Dissertação (Mestrado em Educação). Universidade Federal de Goiás, Goiânia, 2010.

MACIENTE, A. N.; NASCIMENTO, P. A. M. M.; ASSIS, L. R. S. As Ocupaçóes de Nível Superior com Maiores Ganhos Salariais entre 2009 e 2012. Radar: Tecnologia, Produção e Comércio Exterior, Brasília, n. 27, p. 55-68, jul. 2013.

MARX, K. A questão judaica. 2. ed. São Paulo: Moraes, 1991.

MARX, K.; ENGELS, F. A ideologia alemã. Rio de Janeiro: Civilização Brasileira, 2007.

OBSERVATÓRIO DO PNE - Plano Nacional de Educação, 2014. Disponível em: <http://www.observatoriodopne.org.br/>. Acesso em: 26 jul. 2016.

Recebido em 09 de setembro de 2016.

Aprovado em 16 de dezembro de 2016. 